\title{
Gesamt-Inhaltsverzeichnis
}

Erste Abtheilung: Zur theoretischen Philosophie (Bände I und II)

\section{Band 1}

Recension des Aenesidemus (1792) . . . . . . . . . . . 1

Ueber den Begriff der Wissenschaftslehre $\left(1794,1798^{2}\right) \ldots \ldots 27$

Grundlage der gesammten Wissenschaftslehre $\left(1794,1802^{2}\right) \ldots 83$

Grundriss des Eigenthümlichen der Wissenschaftslehre

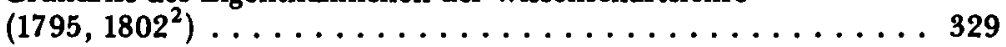

Ueber die Würde des Menschen (1794) . . . . . . . . . . 412

Erste Einleitung in die Wissenschaftslehre (1797) . . . . . . . 417

Zweite Einleitung in die Wissenschaftslehre (1797) . . . . . . 451

Versuch einer neuen Darstellung der Wissenschaftslehre (1797) . . 519

\section{Band II}

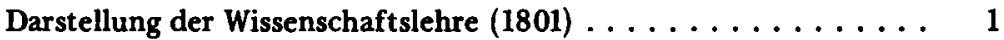

Die Bestimmung des Menschen (1800) . . . . . . . . . . 165

Populairer und kritischer Anhang ............. 321

A. Sonnenklarer Bericht (1801) . . . . . . . . . 323

B. Vergleichung des von Herrn Prof. Schmid aufgestellten Systems mit der Wissenschaftslehre (1795) . . . . . . 421

C. Annalen des philosophischen Tons (1797) . . . . . . . 459

D. Recension von Bardili's Grundriss der ersten Logik (1800) . 490

E. Antwortsschreiben an Herrn Prof. Reinhold (1801) . . . . . 504

Die Thatsachen des Bewusstseyns (1810) . . . . . . . . . 535

Die Wissenschaftslehre in ihrem allgemeinen Umrisse (1810) . . . 693

Zweite Abtheilung (Bände III -V)

A. Zur Rechts- und Sittenlehre (Bände III und IV)

Band III

Grundlage des Naturrechts (1796) $\ldots \ldots \ldots \ldots \ldots \ldots \ldots$

Der geschlossene Handelsstaat (1800) $\ldots \ldots \ldots \ldots \ldots$

Band IV

Das System der Sittenlehre (1798) $\ldots \ldots \ldots \ldots \ldots \ldots \ldots \ldots \ldots$

Die Staatslehre (1813) $\ldots \ldots \ldots \ldots \ldots \ldots \ldots \ldots \ldots \ldots$

Rede an seine Zuhörer (1813) . . . . . . . . . . . . . 601 


\section{B. Zur Religionsphilosophie (Band V)}

\section{Band $V$}

Aphorismen über Religion und Deismus (1790) . . . . . . . . . 1

Versuch einer Kritik aller Offenbarung (1792) . . . . . . . . 9

Ueber den Grund unseres Glaubens an eine göttliche

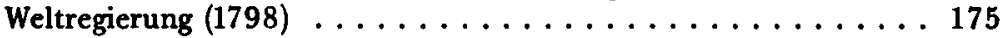

Appellation an das Publicum (1799) $\ldots \ldots \ldots \ldots \ldots 1$

Gerichtliche Verantwortungsschriften gegen die Anklage des

Atheismus (1799) . . . . . . . . . . . . . . . . . . . 239

Rückerinnerungen, Antworten, Fragen (1799) . . . . . . . . 335

Aus einem Privatschreiben (1800) $\ldots \ldots \ldots \ldots \ldots \ldots$

Die Anweisung zum seligen Leben (1806) . . . . . . . . . . 397

Dritte Abtheilung: Populärphilosophische Schriften (Bände VI-VIII)

Band VI (Zur Politik und Moral)

Zurückforderung der Denkfreiheit (1793) . . . . . . . . . . 1

Beitrag zur Berichtigung der Urtheile des Publicums über die

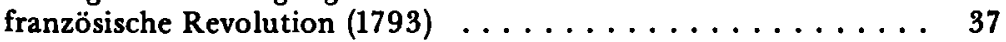

Einige Vorlesungen über die Bestimmung des Gelehrten (1794) . . . 289

Ueber das Wesen des Gelehrten (1805) . . . . . . . . . . . . . 347

Ueber die einzig mögliche Störung der akademischen Freiheit (1811) 449

Band VII (Zur Politik, Moral und Philosophie der Geschichte)

Die Grundzüge des gegenwärtigen Zeitalters (1804) $\ldots \ldots \ldots \ldots$

Reden an die deutsche Nation (1808) . . . . . . . . . 257

Anhang zu den Reden an die deutsche Nation (1806) . . . . . . 503

Anwendung der Beredsamkeit für den gegenwärtigen Krieg . . . 505

Reden an die deutschen Krieger . . . . . . . . . . 509

In Beziehung auf den Namenlosen (Napoleon) . . . . . . . . 512

Politische Fragmente (1807 und 1813) . . . . . . . . . . . 517

Bruchstücke aus einem unvollendeten politischen Werke

vom Jahre 1806-7 . . . . . . . . . . . . . . 519

I. Episode über unser Zeitalter . . . . . . . . . . 519

II. Die Republik der Deutschen . . . . . . . . . . . 530

Aus dem Entwurfe zu einer politischen Schrift im Frühlinge 1813546

Excurse zur Staatslehre (1813) . . . . . . . . . . 574

I. Ueber Errichtung des Vernunftreiches. . . . . . . . . 574

II. Ueber Zufall, Loos, Wunder u.s.w. . . . . . . . . . . . . 590

III. Ueber Ehe, den Gegensatz von altem und neuem Staat

und Religion u.s.w. . . . . . . . . . . . . . . . 597 
Band VIII (Vermischte Schriften und Aufsätze)

Fr. Nicolai's Leben und sonderbare Meinungen (1801) . . . . . . 1 Deducirter Plan einer zu Berlin zu errichtenden höheren

Lehranstalt (1807) . . . . . . . . . . . . . . . . 95

Beilagen zum Universitätsplane . . . . . . . . . . . . 205

I. Plan zu einem periodischen schriftstellerischen Werke an einer deutschen Universität (1805) . . . . . . . . . 207

II. Rede als Decan der philosophischen Fakultät (1811) . . . . 216

Vermischte Aufsätze . . . . . . . . . . . . . . . 221

A. Beweis der Unrechtmässigkeit des Büchernachdrucks (1791) . 223

B. Zwei Predigten aus dem Jahre $1791 \ldots \ldots \ldots \ldots \ldots$

C. Ueber Geist und Buchstab in der Philosophie (1794) . . . . 270

D. Von der Sprachfähigkeit und dem Ursprunge der Sprache (1795) . . . . . . . . . . . . . . . . . . 301

E. Ueber Belebung und Erhöhung des reinen Interesse für

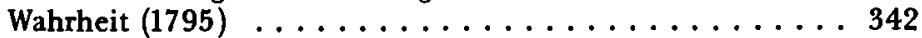

F. Aphorismen über Erziehung (1804) . . . . . . . . 353

G. Bericht über den Begriff der Wissenschaftslehre und die bisherigen Schicksale derselben (1806) . . . . . . . . 361

Recensionen

A. L. Creuzer, Skeptische Betrachtungen über die Freiheit des Willens $(1793) \ldots \ldots \ldots \ldots \ldots \ldots$. . . . . . . . 411

B. F. H. Gebhard, Ueber die sittliche Güte (1793) . . . . . 418

C. I. Kant, Zum ewigen Frieden (1796) . . . . . . . . . 427

Poesien und metrische Ubersetzungen . . . . . . . . . . . 437

A. Das Thal der Liebenden. Eine Novelle (1786) . . . . . . . 439

B. Kleinere Gedichte . . . . . . . . . . . . . . 460

C. Uebersetzungen aus dem Portugicsischen, Spanischen und Italiänischen

Nachgelassene Werke (Bände IX-XI)

Band IX (Nachgelassenes zur theore tischen Philosophie I)

Einleitungsvorlesungen in die Wissenschaftslehre (1813) . . . . . 1

Ueber das Verhältniß der Logik zur Philosophie oder

transscendentale Logik (1812) . . . . . . . . . . . . . . . . . 103

Die Thatsachen des BewuBtseins (1813) . . . . . . . . 401

Band X (Nachgelassenes zur theoretischen Philosophie II)

Die Wissenschaftslehre $(1813) \ldots \ldots \ldots \ldots \ldots 1$

Die Wissenschaftslehre $(1804) \ldots \ldots \ldots \ldots \ldots \ldots$. . . . . 87

Die Wissenschaftslehre (1812) . . . . . . . . . . . 315

Das System der Rechtslehre (1812) . . . . . . . . . . . . 493 
Band XI (Vermischte Schriften aus dem Nachlaß)

Das System der Sittenlehre (1812) _. . . . . . . . . . . . 1

Ascetik als Anhang zur Moral (1798) . . . . . . . . . . . 119

Fünf Vorlesungen über die Bestimmung des Gelehrten (1811) . . . 145

Predigt über Luc. 22,14.15 (1791) . . . . . . . . . . . . . 209

Der Patriotismus und sein Gegentheil (1807) . . . . . . . . . . 221

Ideen für die innere Organisation der Universität Erlangen (1805/6) 275

Tagebuch über den animalischen Magnetismus (1813) . . . . . 295

Vermischte Aufsätze und Fragmente . . . . . . . . . 345

Sonnette .................... 347

Aufsatz, als Einleitung zu einer projektierten philosophischen

Zeitschrift (1806) . . . . . . . . . . . . . . . . . . 349

Sätze zur Erläuterung des Wesens der Thiere (1799 oder 1800) • 362

Bemerkungen bei der Lektüre von Schellings transscendentalem

Idealismus (1800) . . . . . . . . . . . . . . . . 368

Zur Darstellung von Schellings Identitätssysteme (o.J.) . . . . 371

Zu ,Jacobi an Fichte" (1799) . . . . . . . . . . . . 390

Zu Herbarts „Hauptpunkte der Metaphysik" (1808) . . . . . . 395

Ueber Macchiavelli . . . . . . . . . . . . . . . . . . 401 